\title{
PHENOLIC PROFILE OF FRESH AND FROZEN NETTLE, GOUTWEED, DANDELION AND CHICKWEED LEAVES
}

\author{
Ingrida Augspole, Mara Duma, Baiba Ozola, Ingmars Cinkmanis \\ Department of Chemistry, Faculty of Food Technology, Latvia University of Agriculture, Liela iela 2, Jelgava LV-3001, Latvia, \\ e-mail: ingrida.augspole@llu.lv
}

\begin{abstract}
Worldwide it is of great interest to find new and safe antioxidants from natural sources. Green leafy vegetables and wild plant leaves are healthy nutrients, containing vitamins, minerals and biological active compounds, therefore these plants provide beneficial health effects due to the presence of antioxidant compounds. It is useful and popular to supplement human diets with fresh or frozen edible plants. It is known that freezing may help to preserve the quality of plants, and is superior to other preservation methods. The aim of research was to compare the phenolic compounds content of fresh and frozen edible wild plants leaves grown in Latvia. The samples were processed using freezing $-20{ }^{\circ} \mathrm{C}$ and for a comparison fresh samples were analysed. The leaves of stinging nettle (Urtica dioica), common goutweed (Aegopodium podagraria), dandelion (Taraxacum officinale) and chickweed (Stellaria media) were collected in May 2016 in Latvia. In the current research the content of total phenolics was determined in four types of fresh and frozen plant leaves and they can be arranged as follows (starting from plant with less phenolics content as gallic acid equivalent): dandelion<chickweed<goutweed $<$ nettle. The freezing process affected the values of extracted phenolics and results in an increase in the extractability of the polyphenols for about 9.3\%. Using HPLC analysis, we quantified 21 different individual phenols. The eight most abundant phenolics were: catechin hydrate, protocatechnic acid, $\alpha$-resorcylic acid, vanillic acid, sinapic acid, routine, quercetin, luteolin, kaempferol. Experimentally it was ascertained, that in the frozen plant samples contents of some polyphenols increased ( $\mathrm{p}=0.007)$, compared to the fresh samples.
\end{abstract}

Keywords: edible wild plants, phenolic compounds, HPLC.

\section{Introduction}

Wild medicinal plants are used by the majority of the world's population because these plants provide beneficial health effects due to the presence of antioxidant compounds (Dias et al., 2014). Leafy vegetables are rich in natural antioxidants which can neutralize free radicals in the human body. It is generally accepted that therapeutic effects of many plant species including spring wild plants are attributed to the presence of antioxidative phenolics in their tissues. In plants they are involved in numerous roles from structural to protective (Vajic et al., 2015). Beneficial effects of phenolics on human health have been extensively examined and there are studies that prove their protective role in cases of chronic cardiovascular diseases, cancer, and aging (Del Rio et al., 2013). Phenolic compounds are plants secondary metabolites and they are structurally diverse with in excess of 8000 structures having been reported, and many are found in only a limited number of species (Del Rio et al., 2013).

Goutweed (Aegopodium podagraria) is a genus of the Apiaceae family growing in Europe and Asia. The plant is a common weed. Its leaves are used as a spring vegetable like spinach (Orav et al., 2010).

Across the world, there are known more than 1000 plant species of the nettle family (Urticaceae). In Latvia, only two nettle species are found: Urtica dioica L. often called common nettle or stinging nettle, and Urtica urens L. known as annual nettle. Stinging nettle is a perennial herbaceous cosmopolitan plant with long history of usage in treatment of different kinds of health problems (Nencu et al., 2013). Moreover, numerous researches confirmed antiinflammatory, analgesic, antiplatelet, positive cardiovascular and smooth-muscle activity, as well as hypotensive effect of stinging nettles (Upton, 2013). Di Virgilio et al. (2015) reports that nettle can be used as leafy vegetable, it has been used for centuries in salads, pies and soups. Stinging nettle leaves can be used in early spring as a leafy vegetable in salads and soups also in Latvia (Zeipina et al., 2015).

Dandelion Taraxacum officinale $\mathrm{L}$. leaves and roots have been used for medicinal infusions (Ivanov, 2015). Leaves help prevent anemia, because they are rich in iron and helps the fetus to develop a strong liver of its own. Extracts from dandelion possess anti-influenza virus, anti-fertility and strong anti-HIV-1 retrovirus activity, antioxidant and hepatoprotective effects (Ivanov, 2015). Dandelion is important source of cichoric acid with potential application as radical scavengers and metal reducing activity. Therefore, this complex of biologically active substance offers many future applications in field of herbal medicine and nutrition for production of healthy food with wellpronounced healthy effect (Ivanov, 2015).

Chickweed (Stelleria media) is a plant of Eurasian origin which belongs to the order Caryophyllales which comprises several families of herbs and shrubs with simple leaves. These kinds of plants and herbs are of nutritional and medicinal importance (Singh, Yadav, 2010).

Phenolic composition of plants is affected by different factors - variety, genotype, climate, soil, vegetative stage of the plant, harvest time, storage, processing and treatment (Marrelli et al., 2012; Angela, Meireles, 2009). Changes of the content of biologically active compounds in plants can cause climate, and also technological processes applied (Angela, Meireles, 2009). Freezing methods are easily applied and therefore are wildly used, because this method allows the preservation of taste, texture and nutritional 
value of plants. Frozen products are very similar to the original fresh product.

There is insufficient information to conclude that freezing has negative effects on the qualities of plants. The aim of research was to compare the phenolic compounds content of fresh and frozen edible wild plants leaves grown in Latvia.

\section{Materials and Methods}

Investigations were carried out at the Latvia University of Agriculture, Department of Chemistry. Samples of stinging nettle (Urtica dioica), common goutweed (Aegopodium podagraria), dandelion (Taraxacum officinale) and chickweed (Stellaria media) were grown in Latvia, Jelgava region, harvested in April 2016 and stored in polyethylene bags until analysis. In the same day the fresh samples were prepared for analysis. The samples were processed by freezing for seven days at $-20^{\circ} \mathrm{C}$.

Determination of individual polyphenols

The analysis was performed with Shimadzu HPLC system LC-20 Prominence including photo-diode array detector SPD-M20A, solvent delivery unit LC20AD, column oven CTO-20A, autosampler SIL-20A, system controller CBM-20A and data system LC solution software.

The analytical column PerkinElmer C18, $4.6 \mathrm{~mm} \times 250 \mathrm{~mm}, 5 \mu \mathrm{m}$ and temperature of column $30{ }^{\circ} \mathrm{C}$ was used for separation of polyphenols in wavelength of $278 \mathrm{~nm}$. Injection volume of sample $100 \mu \mathrm{L}$. Mobile phase: A (deionized water), B (HPLC grade CHROMASOLV® methanol) and $\mathrm{C}$ (Acetic acid solution for HPLC) in the gradient conditions was

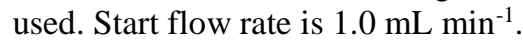

\section{Determination of total phenols}

For total phenols extraction $1.0 \pm 0.001 \mathrm{~g}$ of finely ground plant samples was weighed into volumetric flasks, $10 \mathrm{~mL}$ of extractant, a mixture of methanol, distilled water and hydrochloric acid (79:20:1 v/v/v) was added. The vials were shaked at $20{ }^{\circ} \mathrm{C}$ for $60 \mathrm{~min}$ in the dark, then centrifuged for $10 \mathrm{~min}$ at $5000 \mathrm{rpm}$. The total phenols content of the samples was determined using the Folin-Ciocalteu reagent. To $0.5 \mathrm{~mL}$ of extract $2.5 \mathrm{~mL}$ of Folin-Ciocalteu reagent (diluted 10 times with water) and, after 3 minutes $2 \mathrm{~mL}$ of sodium carbonate $\mathrm{Na}_{2} \mathrm{CO}_{3}\left(75 \mathrm{~g} \mathrm{~L}^{-1}\right)$ was added. The sample was mixed. After 1 hour of incubation at room temperature, the absorbance was measured at $765 \mathrm{~nm}$. Total phenols were expressed as gallic acid equivalents (GAE) $100 \mathrm{~g}^{-1} \mathrm{FW}$ of plant samples.

\section{Results and Discussion}

The presence of phenolic compounds in plant extracts is an important for characterization of plants biological properties. Rappoport (2003) reported that the potency of antioxidants is determined by many factors - the chemical reactivity towards radicals, localization of antioxidants, concentration and mobility at the microenvironment, fate of antioxidant-derived radical, interaction with other antioxidants, and absorption, distribution, retention, metabolism, and safety.

The experimental data showed that content of total phenols in fresh plant samples varied from 510.6 $\pm 25.5 \mathrm{mg}$ GAE $100 \mathrm{~g}^{-1}$ (dandelion) till 743.4 $\pm 96.3 \mathrm{mg}$ GAE $100 \mathrm{~g}^{-1}$ (stinging nettle) (Figure 1). Our results are in accordance with findings of Vajic et al. (2015), Ivanov (2015) and Pinelli et al. (2008), but less than results reported by scientists from University of Baghdad, Iraq (Ghaima et al., 2013). These differences could be explained with other climate conditions.

The freezing process affected the values of extracted phenols and results in an increase in the extractability of the total phenols for about $9.3 \%$. Similar influence of freezing was reported by Tomsone and Kruma (2014).

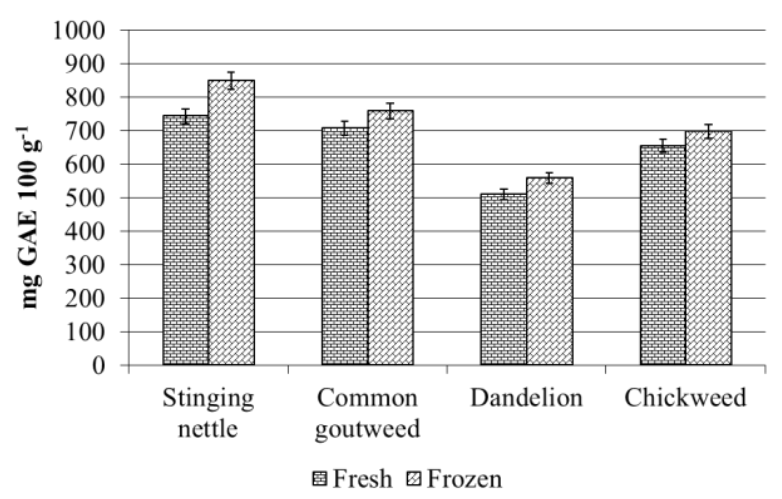

Figure 1. Content of total phenols in plants

The chemical composition of polyphenols compounds in different plants was determined by HPLC. The main polyphenols (Figure 2) in dandelion were sinapic acid $0.97 \pm 0.09 \mathrm{mg} 100 \mathrm{~g}^{-1}$ and kaempferol $0.76 \pm 0.08 \mathrm{mg} 100 \mathrm{~g}^{-1}$, in common goutweed vanillic acid $3.56 \pm 0.15 \mathrm{mg} 100 \mathrm{~g}^{-1}$ and catechin hydrate $1.96 \pm 0.08 \mathrm{mg} 100 \mathrm{~g}^{-1}$, but in chickweed luteolin $0.32 \pm 0.05 \mathrm{mg} 100 \mathrm{~g}^{-1}$.

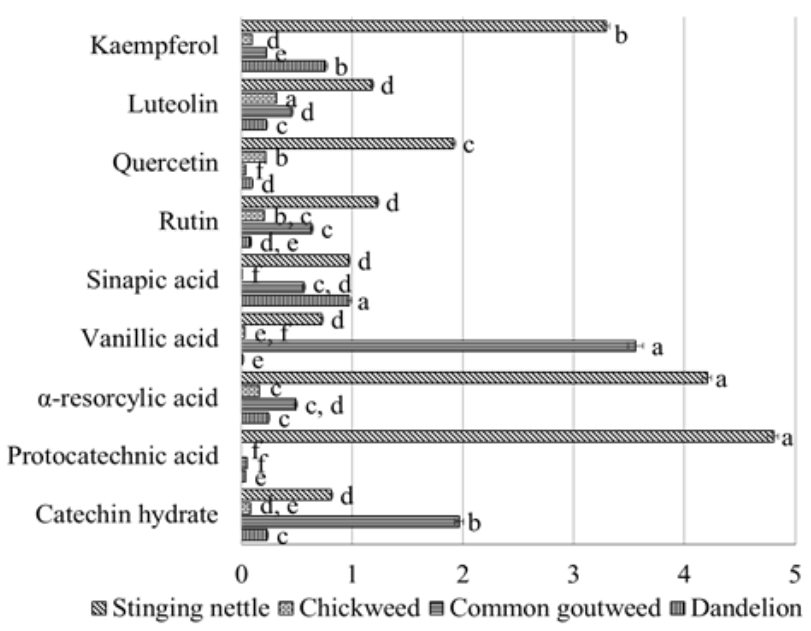

Content of polyphenols, $\mathrm{mg} 100 \mathrm{~g}^{-1}$

Figure 2. Content of polyphenols in fresh plants * mean values within the same column followed by different letters significantly differ according to the LSD test $(p<0.05)$ 
The other compounds were found to be present in small quantities. Experimental results showed that stinging nettle samples are the richest in individual polyphenols compared with other analysed plants. Vajic et al. (2015) reported that predominant phenolic compound in stinging nettle leaves was rutin, but Ghaima et al. (2013) confirmed that the content of phenolic compounds in stinging nettle leaves significantly exceeds those of dandelion leaves.

Freezing is one of the oldest and most widely used method of food preservation, which allows preservation of taste, texture, and nutritional value in foods better than any other method. The freezing process is a combination of the beneficial effects of low temperatures, chemical reactions are reduced, and cellular metabolic reactions are delayed (Delgado, Sun, 2000).

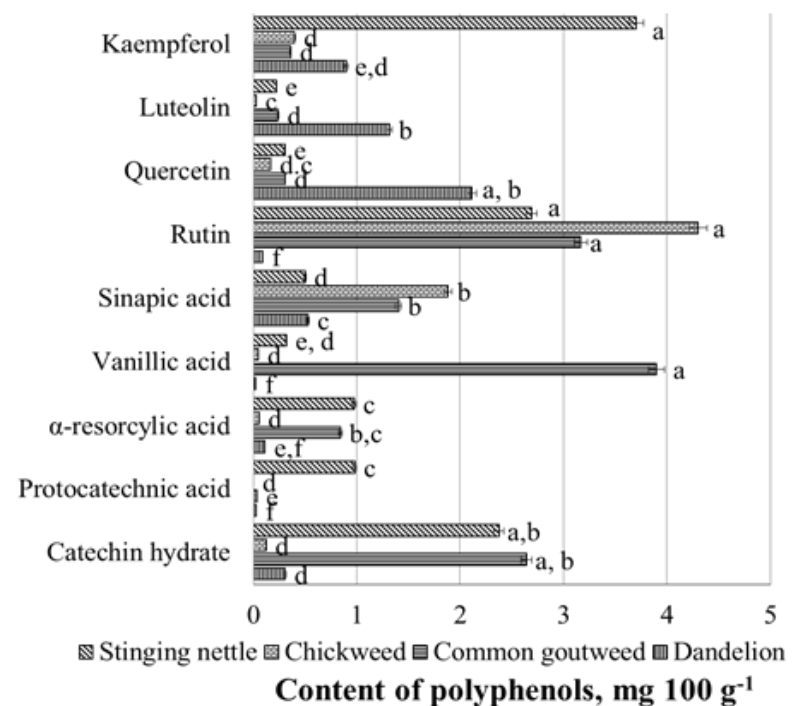

Figure 3. Content of polyphenols in frozen plants

* mean values within the same column followed by different letters significantly differ according to the LSD test $(\mathrm{p}<0.05)$

Analyzing the content of catechin hydrate in frozen stinging nettle (Figure 3) we can conclude that it increased by $66 \%$ and rutin by $54 \%$. The highest increase of quercetin, rutin, sinapic acid, $\alpha$-resorcylic acid and kaempferol content was observed in frozen common goutweed samples - for $88 \%, 80 \%, 60 \%$, $41 \%$ and $38 \%$, respectively. After freezing the higher content of sinapic acid $97 \%$, rutin $95 \%$ and kaempferol $76 \%$ were determined in chickweed samples. The increase of quercetin $99 \%$, luteolin $83 \%$ and catechin hydrate $24 \%$ were observed in dandelion leaves comparing to fresh material.

Also literature studies showed that each phenolic compound behave different depending on treatment method. Content of polyphenols after freezing increased (Mulinaccia et al., 2011).

\section{Conclusions}

The content of total phenols in fresh plant samples could varied from $510.6 \pm 25.5 \mathrm{mg}$ GAE $100 \mathrm{~g}^{-1}$

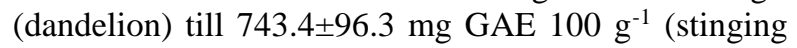

nettle). The freezing process affected the values of extracted phenols and extractability of the polyphenols increases for about $9.3 \%$.

The predominant phenolic acid in plant samples were protocatechnic acid, $\alpha$-resorcylic acid, vanillic acid and kaempferol. Experimentally it was ascertained, that in the frozen plant samples contents of some polyphenols significantly increased $(\mathrm{p}=0.007)$, compared to the fresh samples.

Research on the total phenols and individual polyphenols content showed that freezing is suitable method not only for preserving, but also for more quantitative extraction of these compounds.

\section{References}

1. Angela M., Meireles A. (2009) Extracting Bioactive Compounds for Food Products Theory and Applications. Boca Raton, EUA: CRC Press Taylor \& Francis Group. $466 \mathrm{p}$.

2. Delgado A.E., Sun D.W. (2000) Heat and mass transfer for predicting freezing processes, a review. Journal of Food Engineering. Vol. 47, p. 157-174.

3. Del Rio D., Rodriguez-Mateos A., Spencer J.P.E., Tognolini M., Borges G., Crozier A. (2013) Dietary (poly)phenolics in human health: structures, bioavailability, and evidence of protective effects against chronic diseases. Antioxidants \& Redox Signaling, Vol. 18 (4), p. 1818-1892.

4. Di Virgilio N., Papazoglou E.G., Jankauskiene Z., Di Lonardo S., Praczyk M. Wielgusz K. (2015) The potential of stinging nettle (Urtica dioica L.) as a cropwith multiple uses. Industrial Crops and Products, Vol. 68, p. 42-49.

5. Diasa M.I., Barrosa L., Alvesb R.C., M. Oliveirab B.P.P., Santos-Buelgac C., Ferreiraa I.C.F.R. (2014) Nutritional composition, antioxidant activity and phenolic compoundsof wild Taraxacum sect. Ruderalia. Food Research International. Vol. 56, p. 266-271.

6. Ghaima K.K., Hashim N.M., Ali S.A. (2013) Antibacterial and antioxidant activities of ethyl acetate extract of nettle (Urtica dioica) and dandelion (Taraxacum officinale). Journal of Applied Pharmaceutical Science, Vol. 3 (05), p. 096-099.

7. Ivanov I.G. (2015) Polyphenols Content and Antioxidant Activities of Taraxacum officinale F.H. Wigg (Dandelion) Leaves. International Journal of Pharmacognosy and Phytochemical Research. Vol. 6(4), p. 889-893.

8. Marrelli M., Menichini F., Statti G.A., Bonesi M., Duez P., Menichini F., Conforti F. (2012) Changes in the phenolic and lipophilic composition, in the enzyme inhibition and antiproliferative activity of Ficuscarica L. cultivar Dottato fruits during maturation. Food and Chemical. Toxicology, Vol. 50, p. 726-733.

9. Mulinaccia N., Innocenti M., Bellumori M., Giaccherini C., Martini V., Michelozzi M. (2011) Storage method, drying processes and extraction procedures strongly affect the phenolic fraction of rosemary leaves: An HPLC/DAD/MS study. Talanta, p. 167-176.

10. Nencu I., Istudor V., Ilies D.C., R adulescu V. (2013) Preliminary research regarding the therapeutic uses of Urtica dioica L. Note II. The dynamics of accumulation of total phenolic compounds and ascorbic acid. Farmacia, Vol. 2, p. 276-283. 
11. Orav A., Viitak A., Vaher M. (2010) Identification of bioactive compounds in the leaves and stems of Aegopodium podagraria by various analytical techniques. Procedia Chemistry, Vol. 2, p. 152-160.

12. Pinelli P., Ieri F., Vignolini P., Bacci L., Baronti S., Romani A. (2008) Extraction and HPLC Analysis of Phenolic Compounds in Leaves, Stalks, and Textile Fibers of Urtica dioica L. Journal of Agricultural and Food Chemistry, Vol. 56 (19), p. 9127-9132.

13. Rappoport Z. (2003) The chemistry of phenols. John Wiley and Sons: The Hebrew University, Jerusalem, p. 1667.

14. Singh B., Yadav S.K. (2010) In Vitro studies on antibacterial activity and phytochemical analysis of whole plant extracts of Stelleria media. International Journal of Phytomedicine. Vol. 2, p. 260-266.

15. Tomsone L., Kruma Z. (2014). Influence of freezing and drying on the phenol content and antioxidant activity of horseradish and lovage. In: $9^{\text {th }}$ Baltic Conference on
Food Science and Technology "Food for consumer wellbeing", Conference Proceedings, Jelgava, Latvia, p. 192197.

16. Upton R. (2013) Stinging nettles leaf (Urtica dioica L.): extraordinary vegetable medicine. Journal of Herbal Medicine, Vol. 3, p. 9-38

17. Vajic U.J., Grujic-Milanovic J., Živkovic J., Šavikin K., Godevac D., Miloradovi'c Z., Bugarski B., Stanojevic N.M. (2015) Optimization of extraction of stinging nettle leaf phenolic compounds using response surface methodology. Industrial Crops and Products. Vol. 74, p. 912-917.

18. Zeipina S., Alsina I., Lepse L., Dūma M. (2015) Antioxidant activity in nettle (Urtica dioica L.) and garden orache (Atriplex hortensis L.) leaves during vegetation period. Chemine Technolologija, Vol. 1 (66), p. 1392-1231. 